\title{
PENINGKATAN PRODUKTIVITAS PRODUK SCREW PAN M5X13MM PADA MESIN JBF-06403 DI BAGIAN FORMING DENGAN METODE DEFINE, MEASURE, ANALYZE, IMPROVE, CONTROL (DMAIC) ( STUDI KASUS PT GARUDA METALINDO )
}

\author{
Popy Yuliarty ${ }^{1)}$, Abdul Kholiq ${ }^{2)}$ \\ ${ }^{1), 2)}$ Prodi Teknik Industri, Universitas Mercu Buana
}

\begin{abstract}
Abstrak. PT. GM merupakan perusahaan yang memproduksi baut dan mur. Program improvement quality control circle dilakukan setiap tahun untuk menjaga kualitas dan mengurangi produk defect, namun masih belum maksimal karena tidak konsisten dalam mejalankan program tersebut sehingga defect yang terjadi pada proses pembuatan baut screw pan $\mathrm{m} 5 \times 13 \mathrm{~mm}$ masih sangat tinggi. Penyebab defect pada ini di dominasi oleh $2^{\text {nd }}$ punch patah sebesar $38 \%$ dan $2^{\text {nd }}$ punch retak sebesar $26 \%$ yang akan dikualifikasikan sebagai Critical To Quality/CTQ. Untuk meminimalkan jumlah produk defect dan sekaligus meningkatkan kualitas produk, maka dilakukan penelitian dengan topik meminimalkan produk defect. Tujuan utama dari penelitian ini adalah mengetahui penyebab defect utama dan memberikan usulan perbaikan yang dapat meminimalkan defect. Metode six sigma digunakan dalam upaya meningkatkan kualitas produk melalui tahap DMAIC (Define, Measure, Analyze, Improve dan Control). Hasil penelitian ini adalah pemacahan masalah yang akan dibuat dengan metode $5 \mathrm{~W}+1 \mathrm{H}$. Penyebab defect sebanyak empat jenis yaitu $2^{\text {nd }}$ punch patah, $2^{\text {nd }}$ punch retak, dies kotor, dan flange miring.Usulan perbaikan untuk tiap defect adalah sebanyak 5 rencana.
\end{abstract}

Kata Kunci : $C T Q, D M A I C$, kualitas, , screw pan $\mathrm{m} 5 \times 13 \mathrm{~m}$

Kegiatan produksi merupakan salah satu kegiatan yang utama, juga bisa dikatakan sebagai dapur perusahaan, karena pada kegiatan inilah bahan baku atau input akan diproses dengan bantuan peralatan, mesin, tenaga kerja, serta biaya hingga menjadi produk jadi atau output yang menjadi nilai tambah. Di era industrialisasi saat ini, wacana produktivitas sudah menjadi kewajiban jika hendak memenangkan persaingan dipasar global. Begitu pentingnya masalah ini sehingga tidak heran jika ada banyak perusahaan yang rela mengucurkan sejumlah dana bahkan memasukkannya sebagai budget tahunan untuk meningkatkan produktivitas pada proses produksinya.Untuk dapat tetap bertahan dalam persaingan tersebut, maka salah satu cara yang dilakukan adalah dengan cara mengembangkan sistem produksi yang lebih effisien dan efektif. Kualitas produksi juga berperan penting seiring dengan tingkat persaingan di dunia industri yang semakin meningkat. PT. Garuda Metalindo adalah perusahaan manufaktur yang bergerak dalam pembuatan baut dan mur yang melayani berbagai pelanggan di pasar Original
Equipment Manufacture (OEM) domestik maupun ekspor ke berbagai pasar OEM internasional. Proses forming harus dilalui untuk menghasilkan mur dan baut. Pada proses ini banyak terjadi defect produk, oleh karena itu penelitian ini akan dilakukan pada proses ini. Rumusan masalah dalam penelitian ini adalah bagaimana cara mengetahui presentase defect pada proses forming mesin JBF-06403 di department forming, mengidentifikasi faktor-faktor apa saja yang mempengaruhi defect produk dan tindakan improvement dengan mengguanakan metode Define, Measure, Analyze, Improve and Control (DMAIC).

\section{METODE}

Metode diartikan sebagai cara yang tepat, kemudian penelitian adalah kegiatan ilmiah untuk memperoleh pengetahuan yang benar tentang suatu masalah. Didalam penelitian ini menggunakan model kuantitatif dan model kualitatif atau dengan kata lain model campuran. Flowchart penelitian ini dapat dilihat pada gambar 1 berikut ini : 


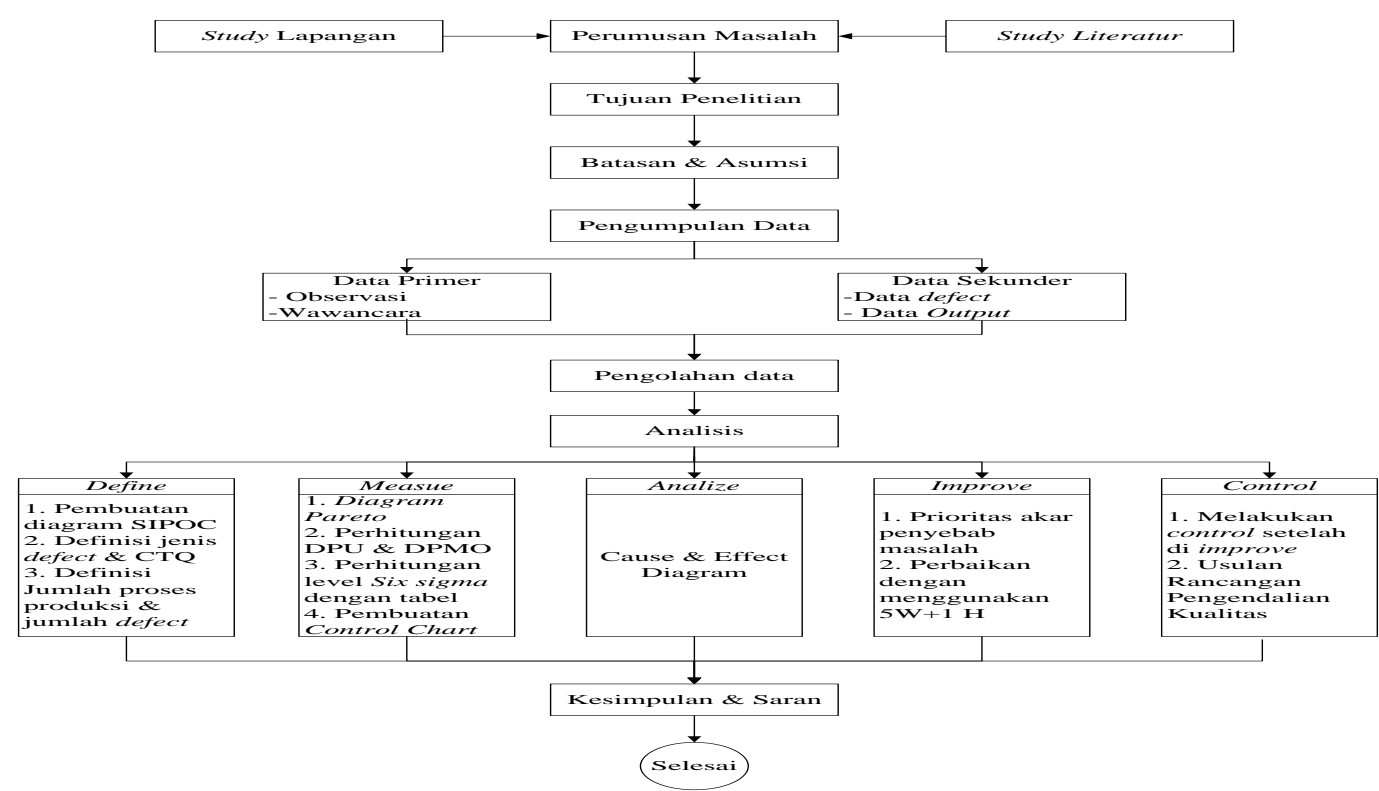

Gambar 1. Flowchart penelitian

\section{HASIL DAN PEMBAHASAN}

Tahap Define. Pada tahap define ini peneliti akan mengidentifikasi kecacatan yang terjadi pada produk Screw Pan M5x13mm. Defect tertiggi pada mesin JBF-06403 sebesar 19809 pcs sedangkan defect terendah terdapat pada mesin JBF-06301 sebesar 1117 pcs (data Mei,Juni dan Juli 2016). Critical To Quality adalah banyaknya produk defect yang paling sering ditemukan pada produk Screw Pan $\mathrm{m} 5 \times 13 \mathrm{~mm}$ adalah : lubang kunci tidak terbentuk/2 $2^{\text {nd }}$ punch patah, flange atas cacat / $2^{\text {nd }}$ punch retak, radius bawah flange cacat /dies kotor dan flange miring. Tahap Measure. pada tahap ini adalah membuat check sheet yang berguna untuk mempermudah proses pengumpulan data serta analisis, untuk mengetahui area permasalahan berdasarkan frekuensi dari jenis atau penyebab dan mengambil keputusan untuk melakukan perbaikan atau tidak. Yang dilakukan dalam tahap ini yaitu: menentukan cacat dominan yang merupakan CTQ dengan menggunakan diagram pareto, mengukur nilai total DPMO dan tingkat sigma. Berikut ini adalah diagram pareto produk screw pan $\mathrm{m} 5 \mathrm{x} 13 \mathrm{~mm}$

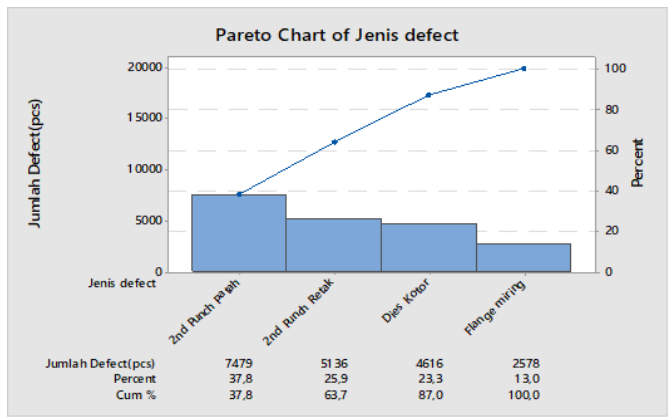

Gambar 2. Diagram pareto produk screw pan $\mathrm{m} 5 \times 13 \mathrm{~mm}$

Perhitungan DPMO (defect permilion opportunity) dan konversi ke level sigma untuk melihat tingkat sigma dapat dilihat pada tabel 1 berikut ini

Tabel 1. Tingkat kapabilitas Six Sigma dan DPMO pada bulan Mei,Juni dan Juli 2016 


\begin{tabular}{lccccc}
\hline Bulan & Output $(p c s)$ & Defect $(p c s)$ & DPU & DPMO & Six sigma \\
\hline Mei & 1031292 & 9469 & 0.00918 & 2,295 & 4.3 \\
Juni & 1202370 & 5723 & 0.00476 & 1,190 & 4.5 \\
Juli & 979058 & 4617 & 0.00472 & 1,179 & 4.5 \\
\hline Total & 3212720 & 19809 & 0.00617 & 1,541 & 4.4 \\
\hline
\end{tabular}

(Sumber : Pengolahan data)

Dari tabel di atas, peneliti akan meminimalkan produk defect screw pan m5x13 mm pada mesin forming dan untuk menaikkan level sigma. Pada Analyze peta kendali $\mathrm{p}$ dilakukan pembuatan peta kendali $\mathrm{P}$ $(P$-Chart) yang berguna untuk mengetahui apakah proses produksi baut screw pan m5x13mm di mesin JBF-06403 dalam keadaan terkendali atau tidak. Dari tahap measure diketahui banyaknya produk defect sebesar 19809 pcs. Tahap Analyze adalah tahap menganalisa, mencari dan menemukan akar penyebab dari suatu masalah. Hal ini dapat dengan menggunakan diagram sebab akibat. Berkaitan dengan pengendalian proses statistik, diagram sebab akibat dipergunakan untuk menunjukan faktor-faktor penyebab dan karakteristik kualitas (akibat) yang disebabkan oleh faktor-faktor penyebab itu (Gasperz, 2003).Tahap Improve adalah tahap perbaikan ini memberikan solusi perbaikan atas masalah dan kegagalan yang terjadi. Usulan perbaikan untuk menyelesaikan akar penyebab dengan menggunakan metode $5 \mathrm{~W}+1 \mathrm{H}$. Tahap improve merupakan bentuk ususlan perbaikan untuk mengurangi terjadinya produk defect pada saat proses sedang berjalan. Tahap Control adalah tahap terakhir dari metode six sigma yang bertujuan untuk mengendalikan proses sehingga berjalan sesuai dengan tujuan awal dan diharapkan tidak akan terulang kembali. Konsep pengendalian yang diberikan pada dasarnya berupa petunjuk kerja atau instruksi kerja pada saat melakukan proses produksi.

\section{KESIMPULAN DAN SARAN}

\section{Kesimpulan}

Berdasarkan penelitian yang maka dapat ditarik kesimpulan sebagai berikut :

1. Defect sebesar 19809 pcs, tingkat DPMO sebesar 1,541 dan rata-rata nilai sigma sebesar 4,5. Faktor penyebab defect dapat dilihat pada table 2: 
Tabel 2. Faktor-Faktor Penyebab Defect Pada Mesin JBF-06403

\begin{tabular}{|c|c|c|c|c|c|c|}
\hline \multirow{2}{*}{ No } & \multirow{2}{*}{$\begin{array}{l}\text { Jenis } \\
\text { defect }\end{array}$} & \multicolumn{5}{|c|}{ Penyebab } \\
\hline & & Manusia & Metode & Mesin & Material & Lingkungan \\
\hline 1 & $\begin{array}{c}2 n d \\
\text { punch } \\
\text { patah }\end{array}$ & $\begin{array}{c}\text { Skill } \\
\text { operator } \\
\text { berbeda } \\
\text { dan kurang } \\
\text { teliti dalam } \\
\text { melakukan } \\
\text { setting }\end{array}$ & $\begin{array}{c}\text { Pengauran } \\
\text { timming } \\
\text { mudah rubah } \\
\text { dan settingan } \\
\text { kuran pas } \\
\text { yang } \\
\text { menimbulkan } \\
\text { mesin tidak } \\
\text { stabil }\end{array}$ & $\begin{array}{l}\text { belum } \\
\text { terdapat } \\
\text { sensor } \\
\text { pendeteksi } \\
2 n d \text { punch } \\
\text { patah }\end{array}$ & $\begin{array}{c}\text { bahan } \\
\text { bengkok }\end{array}$ & \\
\hline 2 & $\begin{array}{l}\text { 2nd } \\
\text { pucnh } \\
\text { retak }\end{array}$ & $\begin{array}{l}\text { Fokus } \\
\text { terganggu } \\
\text { dan } \\
\text { settingan } \\
\text { terburu- } \\
\text { buru }\end{array}$ & $\begin{array}{l}\text { Pemasangan } \\
\text { punch case } \\
\text { kurang pas } \\
\text { dan } \\
\text { pembentukan } \\
\text { no terlalu } \\
\text { padat }\end{array}$ & $\begin{array}{l}\text { Punch case } \\
\text { renggang } \\
\text { tetap di } \\
\text { paksakan }\end{array}$ & & $\begin{array}{c}\text { Penempatan } \\
\text { mesin } \\
\text { grinding } \\
\text { terlalu jauh } \\
\text { dari mesin } \\
\text { forming }\end{array}$ \\
\hline 3 & $\begin{array}{l}\text { Dies } \\
\text { kotor }\end{array}$ & $\begin{array}{c}\text { skill } \\
\text { operator } \\
\text { berbeda- } \\
\text { beda da } \\
\text { kurang } \\
\text { fokus pada } \\
\text { saat setting } \\
\end{array}$ & $\begin{array}{c}\text { sisa gram } \\
\text { nempel di dies } \\
\text { dan griper } \\
\text { kurang center }\end{array}$ & $\begin{array}{l}\text { dies sudah } \\
\text { aus dan } \\
\text { geriper } \\
\text { telalu tebal }\end{array}$ & $\begin{array}{c}\text { Bahan } \\
\text { kotor }\end{array}$ & \\
\hline 4 & $\begin{array}{c}\text { Flange } \\
\text { mring }\end{array}$ & $\begin{array}{l}\text { Setting } \\
\text { produk } \\
\text { terburu- } \\
\text { buru }\end{array}$ & $\begin{array}{c}\text { Pembentukan } \\
\text { belm di diel } \\
\text { dan } \\
\text { pemasangan } \\
\text { punch case } \\
\text { kurang pas } \\
\end{array}$ & $\begin{array}{l}\text { Adjuster } \\
\text { rubah dan } \\
\text { punch case } \\
\text { miring }\end{array}$ & $\begin{array}{l}\text { Material } \\
\text { bengkok }\end{array}$ & \\
\hline
\end{tabular}

2. Pada tahap improve usulan perbaikan dapat dilihat pada table 3 berikut ini :

Table 3. Usulan perbaikan mencegah timbulnya defect

\begin{tabular}{|c|c|c|c|c|c|c|}
\hline \multirow{2}{*}{ No } & \multirow{2}{*}{$\begin{array}{l}\text { Jenis } \\
\text { defect }\end{array}$} & \multicolumn{5}{|c|}{ Ususlan perbaikan } \\
\hline & & Renacana 1 & Rencana 2 & Rencana 3 & Rencana 4 & Rencana 5 \\
\hline 1 & $\begin{array}{l}\text { 2nd punch } \\
\text { patah }\end{array}$ & \begin{tabular}{|c} 
Membuat \\
sensor untuk \\
mendeteksi \\
terjadiya $2 n d$ \\
punch patah
\end{tabular} & $\begin{array}{l}\text { Memaksimalkan } \\
\text { pemakaian, } \\
\text { standart tools dies } \\
\text { sesuai life time } \\
\text { dari tooling }\end{array}$ & $\begin{array}{c}\text { Memebuat } \\
\text { standart } \\
\text { pemakaian } \\
\text { baut timming } \\
\text { / life time }\end{array}$ & $\begin{array}{c}\text { Membuat } \\
\text { standart } \\
\text { setting pada } \\
\text { streightening } \\
\text { setiap } \\
\text { melakukan } \\
\text { pergantian } \\
\text { bahan }\end{array}$ & $\begin{array}{l}\text { Di lakukan } \\
\text { training } \\
\text { setting } \\
\text { yang benar }\end{array}$ \\
\hline
\end{tabular}




\begin{tabular}{|c|c|c|c|c|c|c|}
\hline 2 & $\begin{array}{c}2 \text { nd punch } \\
\text { retak }\end{array}$ & $\begin{array}{c}\text { Modif punch } \\
\text { case } \\
\text { (diameter } \\
\text { lubang } 2 \text { nd } \\
\text { punch } \mathrm{di} \\
\text { perkecil) }\end{array}$ & $\begin{array}{l}\text { Perbaikan pada } \\
\text { seetingan } \\
\text { pembentukan no } \\
2 \text { sesuai standart }\end{array}$ & $\begin{array}{l}\text { Pergantian } \\
\text { seal pada } \\
\text { hidrolic msin } \\
\text { pres secara } \\
\text { berkala }\end{array}$ & $\begin{array}{c}\text { Usulan } \\
\text { penambahan } \\
\text { mesin grinda } \\
\text { pada blok B1 }\end{array}$ & $\begin{array}{c}\text { Trainning } \\
\text { cara setting } \\
\text { yang tepat } \\
\text { dan benar }\end{array}$ \\
\hline 3 & Dies kotor & \begin{tabular}{|c|} 
Menambah \\
jalur lubang \\
angin pada \\
dies no 3
\end{tabular} & $\begin{array}{l}\text { Pemangkasan } \\
\text { griper di bubut }\end{array}$ & $\begin{array}{l}\text { Cek material } \\
\text { kembali } \\
\text { sebelum di } \\
\text { krim ke area } \\
\text { produksi }\end{array}$ & $\begin{array}{l}\text { Membuata } \\
\text { alat bantu } \\
\text { setting }\end{array}$ & $\begin{array}{c}\text { Di lakukan } \\
\text { training dan } \\
\text { membuat } \\
\text { SOP }\end{array}$ \\
\hline 4 & $\begin{array}{l}\text { Flange } \\
\text { miring }\end{array}$ & \begin{tabular}{|c|} 
Membuat \\
standart \\
setting dan \\
membuat life \\
time \\
pemakain \\
baut
\end{tabular} & $\begin{array}{l}\text { Memaksimalkan } \\
\text { dalam melakukan } \\
\text { setting }\end{array}$ & $\begin{array}{l}\text { Membuat } \\
\text { aalat } \\
\text { pemisah } \\
\text { material } \\
\text { yang } \\
\text { tersusun }\end{array}$ & $\begin{array}{l}\text { Di lakukan } \\
\text { training }\end{array}$ & \\
\hline
\end{tabular}

3. Pada tahap control hal hal yang dapat di lakukan adalah

a. Melakukan perawatan pada mesin di blok B1 Forming dan perbaikan mesin secara berkala.

b. Melakuakan pengawasan terhadap bahan baku dan karyawan bagian produksi agar mutu barang yang dihasilkan lebih baik.

c. Melakukan pergantian tools pada komponen mesin sesuai dengan standart life time dan melakukan persiapan apabila kondisi tools sudah mulai aus

d. Melakukan laporan terhadap kepala teknisi apabila terjadi up normal pada mesin yang sudah di improve untuk memaksimalkan sensor agar berjalan dengan optimal.

e. Melakukan jadwal training dalam melakukan setingan pada produk sehingga settingan pada mesin JBF06403 dapat seragam

\section{DAFTAR PUSTAKA}

Aquilano, J. 2001. Operations Management for Competitive Advantage , 9 th Edition, Mc Graw -Hill Companies, Inc., New York Assauri. S. 2004. Manajemen Pemasaran. Jakarta: Rajawali Press.
Bergman \& Klefsjo 1994, Quality: From Customer Needs to Customer Satisfaction, McGraw-Hill Book Company, Europe.

Besterfield, D.H. 2001. Total Quality Management. Edisi 6.New Jersey: Prentice-Hall.

Enamul Kabir S.M. 2013 Productivity Improvement by using Six-Sigma, Volume 3 No. 12

Ferdian,H. \& Yudha Y.A. 2013. Penerapan Metode DMAIC Dalam Peningkatan Acceptance Rate Untuk Produk Panjang Produk Bushing. Vol.4 No. 1.381-393

Gaspersz.V. 2001. "Total Quality Management", Jakarta, PT. Gramedia Pustaka Utama.

Gaspersz, V.2002. Pedoman Implementasi Program Six SigmaTerintegrasi dengan ISO 9001: 2000 MBNQA dan HCCP. Jakarta : PT Gramedia PustakaUtama.

Gaspersz,V. 2003. Manajemen Bisnis Total Total Quality Management. Penerbit PT. Gramedia Pustaka Utama, Jakarta.

Irawan SFI, Pendekatan Metode Six Sigma (DMAIC) Dan Proses Audit (CPPP) Untuk Peningkatan Kualitas di PT.IGP, PASTI UMB Volume VIII No 3, 411 - 422.

Kumar, R. 2013. Reducing Process Variability By Using DMAIC Model ; A Case Study In Bangladesh, VOL 7(1) 127 -140 UDC 65.018

Pande,P 2002, The Six Sigma Way Handbook, Bagaimana GE, Motorolla dan Perusahaan Terkenal Lainnya, Jogyakarta, Penerbit ANDI. 
Ramanan, L. 2014. Six Sigma - DMAIC Framework for Enhancing Quality in
Engineering Educational Institutions, Volume 3 Issue 1 